\title{
The Role of Parental Mediation, Mental Health, High-Risk Behaviors, and Cyberspace Activities in Internet Addiction: A Cross-Sectional Study
}

\author{
Shekoofeh Mottaghi Dasteaee \\ Ardakan University \\ Fahimeh Koohestani \\ Ardakan University \\ Mohammad Hossein Sorbi ( $\square$ Sorbih@gmail.com ) \\ Urmia University https://orcid.org/0000-0001-7161-9888
}

\section{Research article}

Keywords: internet addiction, parental mediation, attachment, depression, self-esteem

Posted Date: February 6th, 2020

DOI: https://doi.org/10.21203/rs.2.22767/v1

License: (c) (i) This work is licensed under a Creative Commons Attribution 4.0 International License. Read Full License 


\section{Abstract}

Background: Today, the Internet provides an important tool to access information and opportunities for learning and entertainment, but its use is not without potential risks. This study investigates the relationship between parental mediation, mental health, high-risk behaviors, and cyberspace activities in Iranian adolescent Internet addiction.

Methods: This was a cross-sectional study that lasted from January 10 to June 14, 2019. The sample consisted of 300 high school students aged 14-17 years in Kerman, Iran. Cluster sampling method was used to collect data. Data were analyzed using SPSS-21 software.

Results: The prevalence of internet addiction disorder in adolescents was $51.7 \%$ (girls $=26.7 \%$ and boys $=25 \%$ ). Chi-square results showed a significant negative relationship between mother's job and internet addiction $(p<0.016)$. The t-test result showed that the role of mediate active parental immunity was more in people with Internet addiction and they experienced more online activities, cyberbullying victimization, substance use, and depression, whereas the role of restrictive mediation, parental attachment and self-esteem were higher in people without internet addiction. Logistic regression showed that variables of online activities OR=1.21 (95\% Cl: 1.12-1.3), cyberbullying victimization OR=1.18 (95\% Cl: 1.04-1.34) and depression OR=1.05 (95\% Cl: 0.99-1.09) had positive effect on Internet addiction, and self-esteem $\mathrm{OR}=0.92$ (95\% Cl: 0.86-0.97) and restrictive parental mediation OR=0.89 (95\% Cl: 0.83-0.97) had negative effect $(p<0.05)$.

Conclusions : The prevalence rate of internet addiction in Iranian adolescents is high which important factors such as inappropriate parental mediation, psychological weakness (such as low self-esteem and depression), high levels of cyber activities, and cyberbullying victimization are considered as important factors to predict this disorder.

Keywords: internet addiction, parental mediation, attachment, depression, self-esteem

\section{Background}

The Internet is a global phenomenon and its influence has steadily increased in recent decades and has become an important part of contemporary life for all age groups (1), so that today it is an important tool for access to information, interaction and entertainment in modern societies. Although digital media offers many benefits such as fast communication, access to information, opportunities for learning and entertainment, and its use is not without potential risks (2). Cyberspace exposes teens and young people to many risky online behaviors, including loss of privacy, access to inappropriate content (such as pornography networks), and aggressive and hostile interaction with peers and adults (3). This inaccurate use of the Internet is often referred to as Internet addiction, which can be described as excessive, uncontrolled, and harmful use of the Internet (4). Internet addiction or behavioral dependence on the Internet whether it is a behavioral disorder, mental disorder or social problem, it is a chronic, recurrent, and widespread phenomenon accompanying serious physical, financial, familial, social and psychological harms. The American Psychiatric Association has defined Internet addiction as a pattern of using the Internet that can lead to dysfunction and unpleasant internal reactions within two months.

Seven criteria have been developed to diagnose this disorder (at least three criteria within two months) including: 1) tolerance 2) signs of withdrawal 3) the time spent on the Internet is more than the considered time, 4) continuing tendency to control behavior 5) spending considerable time on relevant issues 6) reduce social, Occupational and recreational activities due to use of the Internet 7) continuing use, despite awareness of the negative effects. (5). In fact, Internet addiction is an impulse control disorder and a maladaptive pattern of Internet use that can lead to significant clinical discomfort and disruption, causing psychological, educational, and occupational problems in one's life. This disorder in the age group of 15-19 years is more than other age groups $(6,7)$. In Iran, the rate of internet addiction has been reported from $10.8 \%(8)$ to $22.2 \%(9)$. The results of a meta-analysis in 2017 on 130531 samples show that $20 \%$ of Iranians (95\% Cl: 25-16\%) have internet addiction (10). However, adolescent overuse of the Internet is associated with poor social and school performance, low self-esteem, and low life satisfaction (11). So, adolescents with low self-esteem spend more time on social networking sites than people with high selfesteem $(12,13)$. These teens are more likely to be exposed to potential dangers including cyberbullying, harassment and abuse (14). Adolescents who disclose their personal information to strangers or give their passwords to their friends are also more

Page 2/15 
likely to be victims of cyberbullying (15). It should be acknowledged that cyberbullying is a growing phenomenon that seems to be a common feature of interpersonal relationships in adolescence (16). Cyberbullying is defined as "any conduct that occurs through electronic and digital media by individuals and groups that frequently transmit hostile and offensive messages to harm and discomfort others" (17) and is characterized by threatening to offend, Spreading false rumors, manipulating photos, and violating privacy by stealing passwords to access personal information, email, messages, and so on (18).

Given these concepts and definitions, the components of cyber-attack can be summarized in one paragraph: a violent relationship that is intentional and occurs in inappropriate situations and also repeats over time and is not a single event. The attack is mostly occurred through information and communication technology, so its beginning is not always obvious. This last feature distinguishes bullying through technological tools which its negative consequences are equally relevant (19-21).

Adolescents who experience online bullying have greater psychological distress (22), depression and suicidal ideation (25-23), and a higher rate of dropout and delinquency (26) than those who are being victimized in the real world. Adolescents who experience online bullying have more psychological distress (22), depression and suicidal thoughts (25 - 23), and higher rate of dropout and delinquency (26) than those who are being victimized in the real world. Sanders et al. (2000) showed that continued use of the Internet was associated with depression and social isolation among adolescents (27). Depression is a psychological disorder that causes many changes in mood, viewpoint, thinking ability, activity level, perfectionism, and physical processes such as sleep, energy and appetite (28). Symptoms of depression include high levels of sadness, feeling of guilt, feeling of worthlessness, estrangement from others, loss of appetite, decreased libido, insomnia, loss of interest, and lack of enjoyment in daily activities (29). Also, Doty et al. (2017) in their comprehensive study found that all adolescents who were victims of bullying or cyberbullying had a low level of social interaction, especially with their parents (30). The notion that family factors play an important role in the onset and exacerbation of Internet addiction in adolescents has been the source of considerable empirical research. Gunuc and Dogan (2013) point out that Internet addiction is not a problem of one person but a problem that the family is responsible for, and this problem affects the family through its consequences (31). Most parents compare to their children are unskilled in the field of technology but they play a key role in managing their children and they are sure that their children are using the Internet positively. Parents with close relationships with their children were effective in reducing children's online entertainment, social interactions, and erotic motivations as well as Internet addiction (32). Most parents talk to their children about what they do online and sit near the child when they are on the Internet (33).

Therefore, as parents become more involved in parenting styles, adolescents spend less time communicating through social networking sites (SNSs), downloading audio / video programs and searching for fun online news (34). On the other hand, rather than worrying about the online dangers and tight control of children on Internet use, parents should find appropriate mediation strategies to increase children's positive use of the Internet. Parental mediation involves various forms of management and is generally classified into three levels: 1) Restrictive mediation, including parental strategies to control websites or software installed by the child, and the use of electronic devices that restrict the content of sites visited. 2) Evaluation mediation related to the creation of common rules including personal information of children that should not be shared, time spent on the Internet, and sites that may or may not be visited. Unlike the former, the latter involves the active participation of the adolescent in lawmaking (35). 3) Active parental involvement while the child is online involves counseling and helping to use the Internet, recommending sites, or engaging in online activities with children (36). There is considerable evidence that parental monitoring is negatively associated with adolescent Internet addiction $(7,37)$.

A survey on 12- to 17-year-olds adolescents also found that parental monitoring and restrictions reduce online risks in cyberspace (38). In view of the above, the importance of examining the Internet as a new and growing global issue and the role of its influencing factors on psychological, family and social dimensions is one of the most important research needs in any society; because it has some consequences such as: changing lifestyles to spend more time on the Internet, neglecting health, preventing major life activities, diminishing social relationships, ignoring family and friends, financial problems caused by Internet addicts. Therefore, the present study was done considering the increasing number of Internet users among adolescents, and concerns about internet addiction and its detrimental psychological and behavioral effects on adolescents, as well as determining and recognizing the predicting factors of internet addiction. Therefore, the purpose of the present study was to investigate the relationship between parental mediation, mental health, high-risk behaviors, and cyberspace activities in Iranian adolescents. 


\section{Methods}

\section{Study type and Participants}

This was a cross-sectional study that lasted from January 10 to June 14, 2019. The statistical population included all high school adolescents in Kerman, Iran. The sample size was 300 persons according to the number of variables studied. In this study, to ensure that the sample size was sufficient model fitness, we tried to use the maximum sample size for each variable. Finally, after removing invalid and incomplete questionnaires, 300 questionnaires were evaluated. Cluster sampling method was used to select samples.

\section{Instrument}

The following tools were used to collect the data:

\section{a) Online activities}

As in the study of Chang et al. (39), Internet use among adolescents and hours spent online during the week was calculated with two questions.

1. How much time did you spend playing online games over the past weekdays? The answers include: "0 minutes", "1 to 29 minutes", "30 to 59 minutes", "1 hour, less than 2 hours", " 2 hours, less than 3 hours" or "3 hours and more".

2. How much time did you spend on the Internet and online games over the past weekend? The answers include: "0 hours", "1 hour", "2 hours", "3 hours", "4 hours", or "5 hours and more".

\section{b) Parental mediation}

The test was designed by Livingstone et al. (40) in 2011 - 2010 as the online survey on children's Internet use. Parental mediating scales for children's use of the Internet were developed by Dürager and Sonck (41). This test has 5 components: direct mediation in internet use (5 articles), restrictive mediation ( 6 articles), active mediation for internet safety (5 articles), monitoring (4 articles), and technical mediation (4 articles). Reliability of the test by standardized Cronbach's alpha for subscales were as follows: Internet use (0.70); Restrictive mediation (0.89); Active mediation for Internet safety (0.81); Monitoring (0.86); Technical mediation (0.72).

- Response scores for questions 1 to 5 (direct mediation in internet use), 12 to 16 (active mediation for internet safety), 20 to 24 (technical mediation) were respectively: yes $=1$, no=2, I don't know $=0$.

- Response scores for questions 6 to 11 (restrictive Mediation) were respectively: you can always do=1, you can do only under parental permission $=2$, you can never do $=3$, don't know $=0$.

- Response scores for questions 17 to 20 (monitoring) were respectively: Yes=1, No=2, I Don't Know=0, Not True=0.

Dürager and Sonck (2014) confirmed the construct validity of this test by the results obtained from Confirmatory and Exploratory Factor Analysis.

\section{c) Attachment to parents}

As in the study by Chang et al. (39), the following two questions were asked from participants to assess parental attachment:

1. How is your relationship with your mother?

2. How is your relationship with your father?

Responses on a 4-point Likert scale ranged from "Very Bad = 1" to "Very Good = 4" that a high score indicates a high level of attachment to parents.

\section{d) Cyberbullying victimization/perpetration}


As in the study by Chang et al. (2015), 4 items were used to measure sexual harassment. First, the question "Which of the following do you most often do" is asked and then they are asked to answer the following questions.

1. Have you ever send rude comments to online people?

2. Have you ever send embarrassing photos to online people?

3. Have you ever publish rumors or make threatening comments to hurt online people?

4. Have you ever make threatening comments to hurt online people?

Response options include: "Never", "a year ago", "several times in a year", "Several times a month" and "Several times a week". If participants responded "several times a year" or "Repeatedly" to each item, they would be coded as committed cyberbullying.

\section{e) Self-Esteem}

The Rosenberg Self-Esteem Questionnaire was used to assess participants' self-esteem (42). This scale was developed by Rosenberg (1965) and contains 10 items that measure one's overall sense of self-worth or self-acceptance on a 4-point Likert scale (from strongly disagree to strongly agree). To construct this scale, Rosenberg applied it on 5024 high school students in New York State and reported its validity and reliability coefficients of 0.82 and 0.77 , respectively. Rajabi translated this scale into Persian in 2007 and reported its reliability and validity coefficients of 0.84 and 0.72 , respectively. Cronbach's alpha coefficient of this questionnaire was 0.68 in the present study. In a study, Cronbach's alpha coefficients for this scale were 0.87 for males and 0.86 for males at first time. At the second time it was 0.88 for males and 0.87 for females respectively (43). Greenberger (44) reported internal consistency of this scale as 0.84 and test-retest reliability coefficients scale as $0.84,0.67$, and 0.62 , respectively.

\section{f) Beck Depression Inventory- Short form}

The Beck Depression Inventory (BDI-13) was introduced in 1961 by Beck et al. (45). The tool has been developed for measuring various areas of depression such as emotional, cognitive, motivational, and physiological depression, and includes 13 self-report items that express specific symptoms of depression. Each statement in the questionnaire contains a 4-item scale ranging from 0 to 3. The maximum and minimum scores are 39 and zero. Cronbach's alpha coefficient for this questionnaire was reported as 0.87 and retest ability obtained as 0.90 within two weeks. In a factor analysis, researcher identified two factors of negative feeling toward oneself and unpleasant feeling (46). In this study, Cronbach's alpha coefficient of the whole questionnaire was 0.89 and its concurrent validity with Beck Depression Inventory second edition (21 items) was 0.67 . Cronbach's alpha coefficient of this questionnaire was 0.78 in the present study.

\section{g) Smoking and drinking}

As in the study by Chang et al. (39), the following two questions were asked from participants to assess smoking and drinking:

1. Have you ever smoked?

2. Have you ever drunk alcohol?

Response options for each item include: "Never", "A year ago", "Several times a year", "Several times a month", "Several times a week". If participants respond 'several times a year' or 'repeatedly' they are coded as smokers/alcohol users.

\section{h) Harmful use of the Internet}

The questionnaire was developed by Calvo- Francés in 2016 and is one of the newest self-report scales in this domain, which has 12 items and is scored by Likert method. Scores are on a five-point scale from strongly disagree (0) to strongly agree (4). Higher scores on this questionnaire indicate more harmful use of the Internet. The Cronbach's alpha was 0.91 for women and 0.89 for men; indicating very good validity of this test and it also had a split coefficient of 0.86 for both sexes. Also, the results of correlations between this questionnaire and Goldberg's quality of life, anxiety, and depression scales showed that this questionnaire was significantly correlated with these scales. The results of this study show that the scores of this questionnaire are directly correlated with the scores of anxiety and depression, meaning that the higher the scores on the harmful use of the Internet, the higher the scores of anxiety and depression. In contrast, there is an inverse relationship with the quality of life and the higher the score of the harmful use of the Internet, the lower the score of this scale. Although this data does not in any way 
accurately relate to the concept of convergence (the sentence is ambiguous), it does provide indirect evidence of construct validity that is significant (47). Cronbach's alpha coefficient of this questionnaire was 0.72 in the present study.

\section{Results}

\section{Demographic characteristics}

The number of adolescents evaluated in this study was 300 , ranging from 14 to 17 years old. According to the results, $50 \%$ of the study subjects were females and $50 \%$ of the participants were high school students. From 300 families, 107 (35.7\%) had middle income, 106 (35.3\%) had middle-upper income, 53 (17.7\%) had lower income and the rest had upper income. 50.7\% of the mothers had high school diploma and associate degree, $30 \%$ were undergraduate and master, and $19.3 \%$ had middle school degree while $40.7 \%$ of fathers had high school diploma and associate degree, $36.3 \%$ were undergraduate and master, and $23 \%$ had middle school degree. $68 \%$ of mothers were housewives, $24 \%$ employees, and $8 \%$ self-employed.

\section{Correlation matrix of main research variables}

Before determining the causal relationships between predictor variables and the criterion variable, it is necessary to examine the relationship between the predictor variables and the dependent variable, so we used Pearson correlation coefficient. As can be seen in Table 1, there was a significant correlation between all predictor variables and Internet addiction (except for the three variables of active, monitoring, and technical mediation) $(p<0.05)$. It should be noted that since the purpose of the study is to measure the effect of the dependent variable on the predictor variables using logistic regression analysis, the researchers estimating the non-linearity of the predictor variables (independent) by plotting the confidence distribution graph.

\section{Teen features}

Table 2 shows the demographic characteristics of the studied adolescents. Prevalence of internet addiction disorder in participants was $51.7 \%(n=155)$, prevalence in female adolescents was $26.7 \%(n=80)$ and it was $25 \%(n=75)$ in male adolescents. Chi-square results obtained from comparing the frequencies of the two groups with and without internet addiction in five demographic qualitative variables showed that there was no significant difference between the variables of gender, economic status, education of parents of participants, and internet addiction $(p>0.05)$.

Other results in Table 2 showed that mothers' occupation $\left(x^{2}=8.274\right)$ could be related to internet addiction, which is statistically significant. This means that there is a relationship between internet addiction and mother's job $(p<0.05)$. To better understand this relationship, we used a scatter plot.

As it is known, the coefficient of determination calculated in plot 1 is $R 2=0.023$. According to the linear regression coefficient of these two variables, $2.3 \%$ of changes in internet addiction are predictable based on mother's occupation score. That is, by reducing one score on the total score of the mother's job, the average Internet addiction score will increase by 0.12 . Therefore, the lower the job status of mothers, the higher the rate of Internet addiction in adolescents is.

\section{The status of the main variables of research on internet addiction}

Table 3 compares the predictive variables of the research in Internet addiction. The results of the t-test for comparing the two groups show that mediation of active parental safety, online activities, cyberbullying victimization, substance use and depression in Internet addiction group is more than non-Internet addiction group. However, while restricted mediation, parental attachment and self-esteem in individuals without Internet addiction is greater than in people with Internet addiction. These differences were statistically significant $(p<0.01)$. However, there was no significant difference between the variables of active, monitoring and technical mediation in the two groups with and without internet addiction $(p<0.05)$.

\section{Findings of Logistic Regression Analysis in Internet Addiction}

Table 4 presents the results of logistic regression analysis using Logistic Conditional, in which Internet addiction as a dependent variable and predictor variables included demographic information, parental mediation, parental attachment, online activities, cyberbullying victimization, substance use, self-esteem and depression. A total of 300 individuals were included in the analysis, 
and of the predicted variables with a confidence of $51.7 \%$, we would be able to explain the dependent variable of Internet addiction. On the other hand, the Full Model was statistically significant (Chi-square $=101.78, d f=5, p<0.01$ ).

The results of the analysis show that this model is able to explain $28-38 \%$ of the variance of Internet addiction. Also, the overall percentage of correct prediction for the five final predictor variables in the model was $67-76 \%$. Table 4 presents the coefficients and Wald statistics and the possible values for each of the predictor variables. The results show that variables such as online activities, cyberbullying victimization, depression, self-esteem and restricted parental mediation can significantly predict individuals' internet addiction.

As can be seen, online activities among the predictor variables with the $\mathrm{OR}=1.21$ ( $95 \% \mathrm{Cl}: 1.12-1.3$ ) had the most positive and significant effect on adolescent internet addiction $(p<0.001)$. This means that adolescents, who spend more time online, including online activities and online games, are $21 \%$ more likely to be addicted to the Internet. Also, the cyberbullying victimization $\mathrm{OR}=1.18(95 \% \mathrm{Cl}: 1.04-1.34)$ with a probability of $18 \%$ and depression $\mathrm{OR}=1.05(95 \% \mathrm{Cl}: 0.99-1.09)$ with a probability of $5 \%$ had positive and significant effect on adolescent Internet addiction $(p<0.05)$. On the other hand, self-esteem $\mathrm{OR}=0.92(95 \% \mathrm{Cl}: 0.86-0.97)$ with a probability of $8 \%$ and restricted mediation variable OR $=0.89(95 \% \mathrm{Cl}: 0.83-0.97)$ with a probability of $11 \%$ had a significant negative effect on adolescent Internet addiction $(p<0.001)$.

\section{Discussion}

This study investigates the role of parental mediation, mental health, high-risk behaviors, and cyberspace activities in Iranian adolescents' Internet addiction and related factors. The results showed that prevalence of internet addiction disorder among the adolescents was $51.7 \%$ (26.7\% girls, $25 \%$ boys). Therefore, there was no significant difference in males and females regarding internet addiction. The findings also show that active parental mediation, online activities, cyberbullying victimization, substance use, and depression in the Internet addiction group is greater than in the non-Internet addiction group. However, restricted mediation, parental attachment, and self-esteem in individuals without Internet addiction are greater than in those with Internet addiction.

Similar research was conducted by Lee et al. (2013). Their study showed that Internet addiction is associated with smoking and drug use in adolescents, and adolescents who start using drugs at an early age and use multiple substances at the same time are more likely to be at risk for Internet addiction (48).

In addition, Karacic and Oreskovic (49) also found similar results in their study. Their findings showed that the majority of adolescents used the Internet for entertainment, and only one-sixth used it for school / work. Their results also showed that the highest rate of Internet addiction was among 15-16 year-old adolescents. The disadvantages of overusing the Internet are when the user realizes how much time the internet takes and it wastes time to do other tasks such as sleeping and school assignments (1). Jason Sung et al (50) also found in their research that adolescents at high risk of Internet addiction have a high rate of smoking, drinking alcohol, drug use, and sexual intercourse. In the process of Internet addiction, adolescents may experience the negative consequences of Internet addiction such as poor academic performance, parental conflict (37), and social isolation. They may also experience parental rejection, withdrawal from peers in the real world, and low self-esteem at school (51). Parents who have less support and monitoring over adolescents may not be successful in setting adolescents' bedtime and daily schedules and as a result may put them at greater risk for delayed sleep and Internet addiction (52). Also, parents of teenagers with Internet addiction usually impose controls on Internet use, usually resulting in conflict.

Thus, prevention of Internet addiction requires efforts in various sections such as family, school and other social institutions. Family factors such as positive family functioning, parental monitoring, and healthy parent-child relationships have key roles in this process $(53,54)$. In addition, parent-child relationships affect adolescent development. Research has shown that healthy parent-child relationships provides a safe environment for adolescents to express themselves (55), whereas difficult parent-child relationships is often associated with increased adolescent risk behaviors (56).

\section{Conclusion}


The results of this study indicate that the prevalence of internet addiction disorder in Iranian adolescents is high compared to previous years and that parental mediation, adolescent mental health, high-risk behaviors, and cyberspace activities are among important factors in predicting Internet addiction in adolescents. This means that when teens are not monitored properly by their parents, they spend more time on online activities such as the Internet and online games. These activities, in turn, cause cyberbullying victimization and also subject teens to internet overuse and the risk of internet addiction. Given that family and relationships between parents and adolescents have a major impact on adolescent use of the Internet, it is therefore suggested that meetings be held in schools and the need for parent-adolescent relationships be raised and parents become aware of dangers of overusing the Internet. In this regard, the mental health of adolescents is another important factor that increases the risk of internet addiction. Adolescents who have lower self-esteem and are more depressed are more susceptible to Internet addiction. Given that one of the most important causes of adolescent mental illness is their leisure time and teenagers use the Internet to fill it, it is suggested that parents and school officials think and find proper ways to fill this leisure time of adolescent in Iran. The most important advantages of this study were to present the new results of this research in Iran, to present results without bias, and to emphasize the role of family and high-risk behaviors in cyberspace addiction. However, it has limitations such as insufficient information available to compare this study with the results of other studies at home and abroad, the length of the questionnaire questions and the low sample size compared to the total Iranian adolescent population.

\section{Declarations}

\section{Acknowledgments}

This paper has been done in collaboration with Kerman Education Department and Ardakan University. The authors of this article are grateful and thankful to all those who have assisted in the collection of the research data.

\section{Funding}

This research was funded by a grant from Ardakan University project.

\section{Availability of data and materials}

The datasets used during the current study are available from the corresponding author on reasonable request.

\section{Ethics approval and consent to participate}

This paper has the approval of research ethics committee of Ardakan University (2345). All procedures performed in studies involving human participants were in accordance with the ethical standards of the national research committee. All participants and their guardians gave written informed consent before the study.

\section{Consent for publication}

Not applicable.

\section{Conflict of Interest}

There is no conflict of interest to declare.

\section{Competing interests}

The authors declare that they have no competing interests.

\section{Authors' contributions}

MHS and SMD contributed to performing all data analyses. FK contributed data analysis tools and technical support. MHS and FK contributed to creating the design of the study and data analyses and writing the manuscript; they should be regarded as the corresponding authors. All authors read and approved the final manuscript. 


\section{References}

1. Sinkkonen H-M, Puhakka H, Meriläinen M. Internet use and addiction among Finnish Adolescents (15-19 years). Journal of adolescence. 2014;37(2):123-31.

2. Machimbarrena J, Calvete E, Fernández-González L, Álvarez-Bardón A, Álvarez-Fernández L, González-Cabrera J. Internet risks: An overview of victimization in cyberbullying, cyber dating abuse, sexting, online grooming and problematic internet use. International journal of environmental research and public health. 2018;15(11):2471.

3. Subrahmanyam K, Šmahel D. The Darker Sides of the Internet: Violence, Cyber Bullying, and Victimization. Digital Youth: Springer; 2011. 179-99.

4. Dalbudak E, Evren C, Aldemir S, Coskun KS, Ugurlu H, Yildirim FG. Relationship of internet addiction severity with depression, anxiety, and alexithymia, temperament and character in university students. Cyberpsychology, Behavior, and Social Networking. 2013;16(4):272-8.

5. Fitzpatrick JJ. Internet addiction: recognition and interventions. Archives of psychiatric nursing. 2008;22(2):59-60.

6. Mohamadbeigi A, Ghazavi A, Ghamari F, Saeidi A. Effect of internet addiction on educational status of Arak University of medical sciences students, spring 2009. Journal of Arak University of Medical Sciences. 2010;12(4):95-102.

7. Xu J, Shen L-x, Yan C-h, Hu H, Yang F, Wang L, et al. Personal characteristics related to the risk of adolescent internet addiction: a survey in Shanghai, China. BMC public health. 2012;12(1):1106.

8. Ghamari F, Mohammadbeigi A, Mohammadsalehi N, Hashiani AA. Internet addiction and modeling its risk factors in medical students, Iran. Indian journal of psychological medicine. 2011;33(2):158.

9. Ahmadi K. Internet addiction among Iranian adolescents: a nationwide study. Acta Medica Iranica. 2014;52(6):467-72.

10. Modara F, Rezaee-Nour J, Sayehmiri N, Maleki F, Aghakhani N, Sayehmiri K, et al. Prevalence of internet addiction in Iran: a systematic review and meta-analysis. Addiction \& health. 2017;9(4):243-52.

11. Lai C, Mak K, Watanabe H, Jeong J, Kim D, Bahar N, et al. The mediating role of Internet addiction in depression, social anxiety, and psychosocial well-being among adolescents in six Asian countries: a structural equation modelling approach. Public health. 2015;129(9):1224-36.

12. Ellison NB, Steinfield C, Lampe C. The benefits of Facebook "friends:" Social capital and college students' use of online social network sites. Journal of computer-mediated communication. 2007;12(4):1143-68.

13. Steinfield C, Ellison NB, Lampe C. Social capital, self-esteem, and use of online social network sites: A longitudinal analysis. Journal of Applied Developmental Psychology. 2008;29(6):434-45.

14. Sasson H, Mesch G. The role of parental mediation and peer norms on the likelihood of cyberbullying. The Journal of genetic psychology. 2017;178(1):15-27.

15. Kowalski RM, Giumetti GW, Schroeder AN, Lattanner MR. Bullying in the digital age: A critical review and meta-analysis of cyberbullying research among youth. Psychological bulletin. 2014;140(4):1073.

16. Smith PK, del Barrio C, Tokunaga RS. Defi nitions of Bullying and Cyberbullying: How Useful Are the Terms? Principles of Cyberbullying Research: Routledge; 2012. 54-68.

17. Tokunaga RS. Following you home from school: A critical review and synthesis of research on cyberbullying victimization. Computers in human behavior. 2010;26(3):277-87.

18. Lanzillotti Al, Korman GP. Cyberbullying, características y repercusiones de una nueva modalidad de maltrato escolar. 2014.

19. Avilés JM, Irurtia MJ, García-Lopez LJ, Caballo VE. El maltrato entre iguales:" bullying". Psicología Conductual. 2011;19(1):57.

20. Rodriguez JH, Gregus SJ, Craig JT, Pastrana FA, Cavell TA. Bullied children. Comprehensive evidence based interventions for children and adolescents. 2014:301-16.

21. Caballo VE, Arias B, Salazar IC, Calderero M, Irurtia MJ, Ollendick TH. Un nueva medida de autoinforme para evaluar la ansiedad/fobia social en niños: el "Cuestionario de ansiedad social para niños"(CASO-N24). Behavioral Psychology/Psicología Conductual. 2012;20(3):485-504. 
22. Ybarra ML, Mitchell KJ, Wolak J, Finkelhor D. Examining characteristics and associated distress related to Internet harassment: findings from the Second Youth Internet Safety Survey. Pediatrics. 2006;118(4):e1169-e77.

23. Bonanno RA, Hymel S. Cyber bullying and internalizing difficulties: Above and beyond the impact of traditional forms of bullying. Journal of youth and adolescence. 2013;42(5):685-97.

24. Schneider SK, O'donnell L, Stueve A, Coulter RW. Cyberbullying, school bullying, and psychological distress: A regional census of high school students. American journal of public health. 2012;102(1):171-7.

25. Van Geel M, Vedder P, Tanilon J. Relationship between peer victimization, cyberbullying, and suicide in children and adolescents: a meta-analysis. JAMA pediatrics. 2014;168(5):435-42.

26. Ybarra ML, Diener-West M, Leaf PJ. Examining the overlap in Internet harassment and school bullying: Implications for school intervention. Journal of Adolescent Health. 2007;41(6):S42-S50.

27. Sanders CE, Field TM, Diego M, Kaplan M. The relationship of Internet use to depression and social isolation among adolescents. Adolescence. 2000;35(138):237.

28. Fayyaz F, Sarmast Z, Ehsan HB, Okhovvat A, Fayyaz R. Preliminary construction of depression diagnosis scale based on Quran and investigation of its psychometric characteristics.

29. Davidson L, Shahar G, Stayner DA, Chinman MJ, Rakfeldt J, Tebes JK. Supported socialization for people with psychiatric disabilities: Lessons from a randomized controlled trial. Journal of Community Psychology. 2004;32(4):453-77.

30. Doty JL, Gower AL, Rudi JH, McMorris BJ, Borowsky IW. Patterns of bullying and sexual harassment: Connections with parents and teachers as direct protective factors. Journal of youth and adolescence. 2017;46(11):2289-304.

31. Gunuc S, Dogan A. The relationships between Turkish adolescents' Internet addiction, their perceived social support and family activities. Computers in Human Behavior. 2013;29(6):2197-207.

32. Chin Hooi P. Influence of parents and peers on Internet usage and addiction amongst school-going youths in Malaysia. ProQuest Dissertations and Theses,(January). 2011.

33. Livingstone S, Haddon L, Görzig A, Ólafsson K. Risks and safety on the internet: the perspective of European children: full findings and policy implications from the EU Kids Online survey of 9-16 year olds and their parents in 25 countries. 2011.

34. Leung L, Lee PS. The influences of information literacy, internet addiction and parenting styles on internet risks. New Media \& Society. 2012;14(1):117-36.

35. Mesch GS. The family and the Internet: The Israeli case. Social Science Quarterly. 2003;84(4):1038-50.

36. Lee S-J, Chae Y-G. Children's Internet use in a family context: Influence on family relationships and parental mediation. Cyberpsychology \& behavior. 2007;10(5):640-4.

37. Yen J-Y, Yen C-F, Chen C-C, Chen S-H, Ko C-H. Family factors of internet addiction and substance use experience in Taiwanese adolescents. CyberPsychology \& Behavior. 2007;10(3):323-9.

38. Khurana A, Bleakley A, Jordan AB, Romer D. The protective effects of parental monitoring and internet restriction on adolescents' risk of online harassment. Journal of youth and Adolescence. 2015;44(5):1039-47.

39. Chang F-C, Chiu C-H, Miao N-F, Chen P-H, Lee C-M, Chiang J-T, et al. The relationship between parental mediation and Internet addiction among adolescents, and the association with cyberbullying and depression. Comprehensive psychiatry. 2015;57:21-8.

40. Livingstone S, Haddon L, Görzig A, Ólafsson K. Technical report and user guide: The 2010 EU kids online survey. 2011.

41. Dürager A, Sonck N. Testing the reliability of scales on parental internet mediation. 2014.

42. Rosenberg M. Society and the adolescent self-image Princeton, NJ: Princeton Univer. Press Google Scholar| Crossref. 1965.

43. Mäkikangas A, Kinnunen U, Feldt T. Self-esteem, dispositional optimism, and health: Evidence from cross-lagged data on employees. Journal of research in personality. 2004;38(6):556-75.

44. Greenberger E, Chen C, Dmitrieva J, Farruggia SP. Item-wording and the dimensionality of the Rosenberg Self-Esteem Scale: Do they matter? Personality and individual differences. 2003;35(6):1241-54.

45. Beck A, Ward C, Mendelson M, Mock J, Erbaugh J. An Inventory for Measuring Depression. Archives of General Psychiatry, Vol. 4. 1961.

Page $10 / 15$ 
46. Rajabi GR. Psychometric properties of Beck depression inventory short form items (BDI-13). Journal of Iranian Psychologists. 2005;1(4):291-8.

47. Calvo-Francés F. Internet abusive use questionnaire: psychometric properties. Computers in Human Behavior. 2016;59:18794.

48. Lee YS, Han DH, Kim SM, Renshaw PF. Substance abuse precedes internet addiction. Addictive behaviors. 2013;38(4):20225.

49. Karacic S, Oreskovic S. Internet addiction through the phase of adolescence: a questionnaire study. JMIR mental health. 2017;4(2):e11.

50. Sung J, Lee J, Noh H-M, Park YS, Ahn EJ. Associations between the risk of internet addiction and problem behaviors among Korean adolescents. Korean journal of family medicine. 2013;34(2):115.

51. Ko C-H, Liu T-L, Wang P-W, Chen C-S, Yen C-F, Yen J-Y. The exacerbation of depression, hostility, and social anxiety in the course of Internet addiction among adolescents: a prospective study. Comprehensive Psychiatry. 2014;55(6):1377-84.

52. Lin Y-H, Gau SS-F. Association between morningness-eveningness and the severity of compulsive Internet use: the moderating role of gender and parenting style. Sleep medicine. 2013;14(12):1398-404.

53. Shi X, Wang J, Zou H. Family functioning and Internet addiction among Chinese adolescents: The mediating roles of selfesteem and loneliness. Computers in Human Behavior. 2017;76:201-10.

54. Siomos K, Floros G, Fisoun V, Evaggelia D, Farkonas N, Sergentani E, et al. Evolution of Internet addiction in Greek adolescent students over a two-year period: the impact of parental bonding. European child \& adolescent psychiatry. 2012;21(4):211-9.

55. Shek DT, Law MY. Parental behavioral control, parental psychological control and parent-child relational qualities: relationships to Chinese adolescent risk behavior. Chinese Adolescents in Hong Kong: Springer; 2014. p. 51-69.

56. Wang B, Stanton B, Li X, Cottrell L, Deveaux L, Kaljee L. The influence of parental monitoring and parent-adolescent communication on Bahamian adolescent risk involvement: A three-year longitudinal examination. Social Science \& Medicine. 2013;97:161-9.

\section{Tables}




\begin{tabular}{|c|c|c|c|c|c|c|c|c|c|c|c|c|}
\hline Variables & 1 & 2 & 3 & 4 & 5 & 6 & 7 & 8 & 9 & 10 & 11 & 12 \\
\hline 1. Active use & - & & & & & & & & & & & \\
\hline $\begin{array}{l}\text { 2. Active } \\
\text { safety }\end{array}$ & $0.36^{\star \star}$ & - & & & & & & & & & & \\
\hline $\begin{array}{l}3 . \\
\text { Monitoring }\end{array}$ & $0.25^{\star \star}$ & 0.08 & - & & & & & & & & & \\
\hline 4. Technical & $0.22^{\star \star}$ & $0.26^{\star \star}$ & $0.30^{\star \star}$ & - & & & & & & & & \\
\hline 5. Restrictive & -0.07 & -0.10 & $-0.14^{\star *}$ & -0.05 & - & & & & & & & \\
\hline $\begin{array}{l}\text { 6. Parental } \\
\text { attachment }\end{array}$ & $-0.14^{\star}$ & $-0.27^{\star \star}$ & -0.02 & $-0.13^{*}$ & 0.08 & - & & & & & & \\
\hline $\begin{array}{l}\text { 7. Online } \\
\text { activates }\end{array}$ & $0.14^{*}$ & 0.08 & 0.07 & $-0.13^{*}$ & $-0.27^{\star \star}$ & 0.08 & - & & & & & \\
\hline $\begin{array}{l}\text { 8. Cyber- } \\
\text { bullying } \\
\text { victimization }\end{array}$ & $0.14^{*}$ & $0.21^{\star \star}$ & 0.03 & $0.14^{\star}$ & $-0.18^{\star *}$ & $-0.17^{\star *}$ & $0.17^{\star \star}$ & - & & & & \\
\hline $\begin{array}{l}9 . \\
\text { Substance } \\
\text { use }\end{array}$ & $0.12^{*}$ & $0.23^{\star \star}$ & -0.04 & $0.13^{*}$ & $0.37^{\star \star}$ & $0.27^{\star \star}$ & $0.27^{\star \star}$ & $0.43^{\star \star}$ & - & & & \\
\hline $\begin{array}{l}10 . \text { Self- } \\
\text { esteem }\end{array}$ & $-0.14^{\star \star}$ & $-0.22^{\star \star}$ & 0.6 & 0.05 & 0.10 & $0.37^{\star \star}$ & $0.21^{\star \star}$ & $-0.15^{\star \star}$ & $-0.35^{\star \star}$ & - & & \\
\hline $\begin{array}{l}11 . \\
\text { Depression }\end{array}$ & $0.13^{\star}$ & $0.21^{* *}$ & -0.05 & 0.06 & $-0.21^{\star \star}$ & $-0.39^{\star *}$ & $0.22^{\star \star}$ & $0.28^{\star \star}$ & $0.35^{\star \star}$ & $-0.56^{* *}$ & - & \\
\hline $\begin{array}{l}\text { 12. Internet } \\
\text { addiction }\end{array}$ & 0.08 & $0.24^{\star *}$ & 0.05 & 0.06 & $-0.39^{\star \star}$ & $-0.23^{\star \star}$ & $0.48^{\star \star}$ & $0.30^{\star \star}$ & $0.37^{\star \star}$ & $-0.44^{\star *}$ & $0.43^{\star *}$ & - \\
\hline
\end{tabular}




\begin{tabular}{|c|c|c|c|c|c|c|}
\hline \multirow[t]{2}{*}{ Variables } & \multicolumn{2}{|c|}{ Non-Internet addiction } & \multicolumn{2}{|c|}{ Internet addiction } & \multicolumn{2}{|c|}{ Chi-square } \\
\hline & $\mathbf{N}$ & $\%$ & $\mathbf{N}$ & $\%$ & Value & Sig. \\
\hline Gender & & & & & 0.334 & 0.563 \\
\hline Male & 75 & 51.7 & 75 & 48.4 & & \\
\hline Female & 70 & 48.3 & 80 & 51.6 & & \\
\hline School grade & & & & & 2.256 & 0.133 \\
\hline $9^{\text {th }}$ grade & 79 & 54.5 & 71 & 45.8 & & \\
\hline $10^{\text {th }}$ grade & 66 & 45.5 & 84 & 54.2 & & \\
\hline Economic status & & & & & 1.699 & 0.637 \\
\hline lower & 22 & 15.2 & 31 & 20 & & \\
\hline Meddle & 56 & 38.6 & 51 & 32.9 & & \\
\hline Middle-Upper & 51 & 35.2 & 55 & 35.5 & & \\
\hline Upper & 16 & 11 & 18 & 11.6 & & \\
\hline Mother's education & & & & & 2.691 & 0.260 \\
\hline Middle school & 26 & 17.9 & 32 & 20.6 & & \\
\hline High school Diploma & 69 & 47.6 & 83 & 53.6 & & \\
\hline Undergraduate \& Master & 50 & 34.5 & 40 & 25.8 & & \\
\hline Father's education & & & & & 1.372 & 0.504 \\
\hline Middle school & 35 & 24.1 & 34 & 21.9 & & \\
\hline High school Diploma & 54 & 37.2 & 68 & 43.9 & & \\
\hline Undergraduate \& Master & 56 & 38.7 & 53 & 34.2 & & \\
\hline Mother's job & & & & & 8.274 & $<0.016$ \\
\hline Housewife & 87 & 60 & 117 & 75.5 & & \\
\hline Employee & 45 & 31 & 29 & 18.7 & & \\
\hline Self-employment & 13 & 9 & 9 & 5.8 & & \\
\hline
\end{tabular}




\begin{tabular}{|c|c|c|c|c|c|c|}
\hline \multirow[t]{2}{*}{ Variables } & \multicolumn{2}{|c|}{ Non-Internet addiction } & \multicolumn{2}{|c|}{ Internet addiction } & \multicolumn{2}{|l|}{ t-test } \\
\hline & Mean & SD & Mean & SD & $t$ & Sig. \\
\hline \multicolumn{7}{|l|}{ Parental mediation } \\
\hline Active use & 6.80 & 1.94 & 7.08 & 1.80 & -0.836 & 0.404 \\
\hline Active safety & 5.89 & 2.18 & 6.65 & 2.04 & -3.118 & $<0.002$ \\
\hline Monitoring & 5.06 & 2.35 & 5.14 & 1.91 & -0.321 & 0.748 \\
\hline Technical & 4.80 & 2.74 & 5.09 & 2.35 & -1.001 & 0.317 \\
\hline Restrictive & 10.44 & 4.01 & 8.27 & 3.06 & 5.225 & $<0.0001$ \\
\hline Parental attachment & 7.37 & 0.98 & 6.84 & 1.27 & 4.095 & $<0.0001$ \\
\hline Online activities & 2.77 & 3.13 & 5.76 & 3.73 & -7.543 & $<0.0001$ \\
\hline Cyber-bullying victimization & 0.77 & 2.10 & 2.27 & 3.20 & -4.818 & $<0.0001$ \\
\hline Substance use & 0.34 & 1.05 & 1.32 & 1.89 & -5.603 & $<0.0001$ \\
\hline Self-esteem & 21.06 & 5.10 & 17.40 & 5.33 & 6.074 & $<0.0001$ \\
\hline Depression & 4.15 & 5.79 & 9.60 & 8.39 & -6.571 & $<0.0001$ \\
\hline
\end{tabular}

\begin{tabular}{|lllllll|}
\hline \multicolumn{7}{|l|}{ Table 4. Results of logistic regression analysis in internet addiction } \\
\hline Variables & B & S.E & Wald & Sig. & O.R & 95\% Cl \\
\hline Restrictive & -0.109 & 0.040 & 7.50 & 0.006 & 0.89 & $0.83-0.97$ \\
\hline Online activates & 0.191 & 0.040 & 23.11 & 0.001 & 1.21 & $1.12-1.31$ \\
\hline Cyber-bullying victimization & 0.167 & 0.063 & 7.11 & 0.008 & 1.18 & $1.04-1.34$ \\
\hline Self-esteem & -0.087 & 0.032 & 7.39 & 0.007 & 0.92 & $0.86-0.97$ \\
\hline Depression & 0.046 & 0.024 & 3.72 & 0.050 & 1.05 & $0.99-1.09$ \\
\hline
\end{tabular}

Figures 


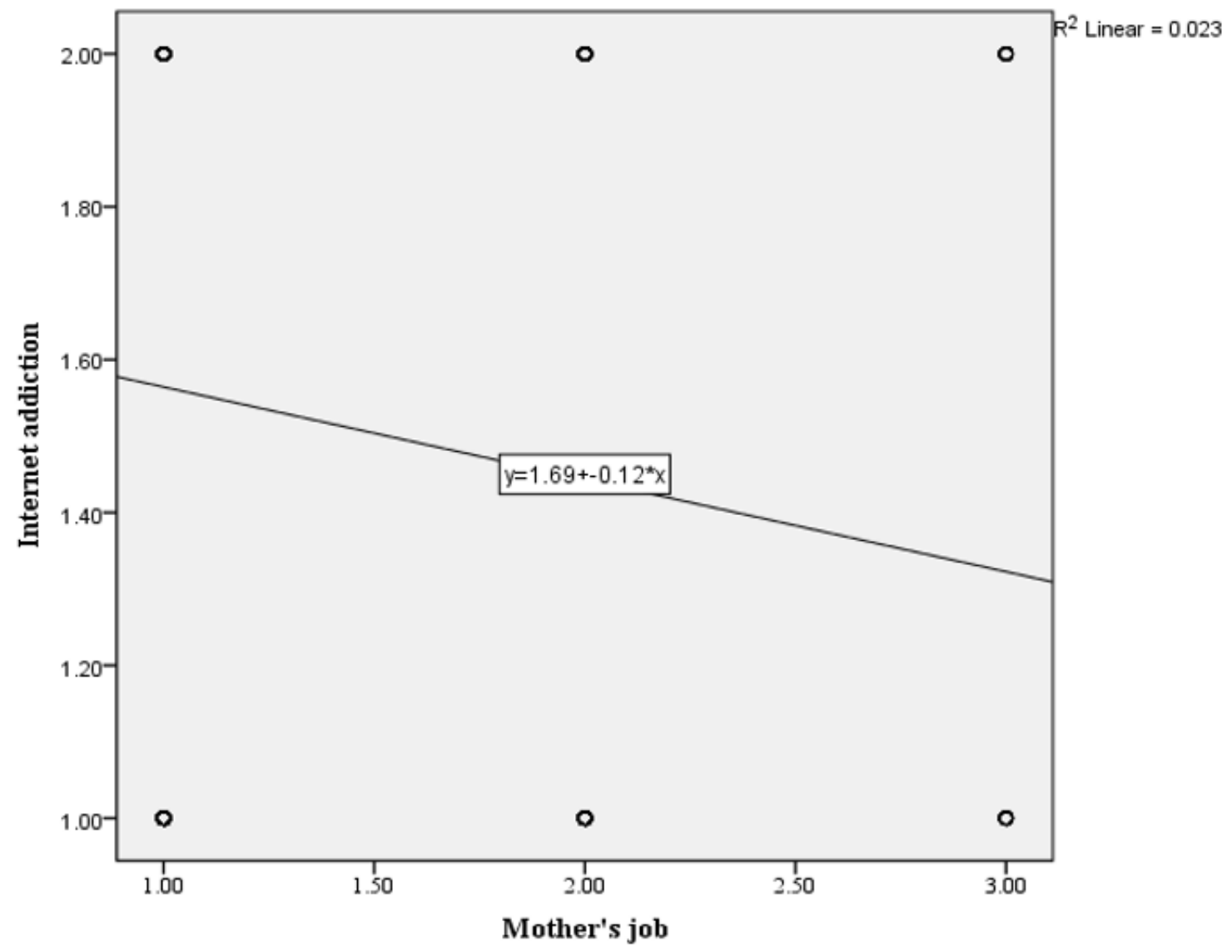

Figure 2

The role of mother's job on internet addiction 